Revista

Ibero-Americana

de Estratégıa

\title{
PROCESSOS DE IMPLEMENTAÇÃO DE ESTRATÉGIAS DE MARKETING NA INDÚSTRIA CRIATIVA DE JOGOS ELETRÔNICOS
}

\author{
MARKETING STRATEGY IMPLEMENTATION PROCESS IN THE CREATIVE \\ INDUSTRY OF VIDEO GAMES
}

PROCESOS DE APLICACIÓN DE ESTRATEGIAS DE MARKETING EN LA INDUSTRIA CREATIVA DE VIDEO JUEGOS

\section{Maryangela Drumond de Abreu Negrão}

Mestre em Administração pela Universidade Federal do Paraná - UFPR

E-mail: mary.drumond @terra.com.br (Brasil)

\section{Ana Maria Machado Toaldo}

Doutora em Administração pela Escola de Administração da Universidade Federal do Rio Grande do Sul - UFRGS

Professora do Programa de Pós Graduação em Administração da Universidade Federal do Paraná PPGADM /UFPR

E-mail: anatoaldo@ufpr.br (Brasil) 
Processos de Implementação de Estratégias de Marketing na Indústria Criativa de Jogos Eletrônicos

\title{
PROCESSOS DE IMPLEMENTAÇÃO DE ESTRATÉGIAS DE MARKETING NA INDÚSTRIA CRIATIVA DE JOGOS ELETRÔNICOS
}

\section{RESUMO}

Este artigo colabora com o conhecimento sobre processo de estratégia de marketing, ao apresentar fatores organizacionais e humanos que suportam os processos de implementação, identificados em pesquisa qualitativa realizada junto à indústria criativa desenvolvedora de jogos eletrônicos. A investigação, um estudo de casos aplicado a quatro estúdios de videogames, foi baseada no Modelo Implementação de Estratégia de Marketing, de Sashittal e Jassawalla (2001) e nos conceitos de comportamento criativo e inovação nas organizações propostos por Amabile (1997). A análise aponta que a implementação de estratégias de marketing está ancorada em padrões de gestão inovadores, nas habilidades criativas e na adoção de modernas técnicas de controles. Observou-se que uma visão que associa produção, processo, orientação para o mercado e entrega de valor é essencial para a implementação de estratégias de marketing em estruturas organizacionais criativas e inovadoras. Essa investigação contribui com os estudos de implementação de marketing em ambientes criativos e inovadores sob a perspectiva de pequenas empresas e com a teoria de estratégia quando sugere que em futuras investigações a análise do processo, o controle e as habilidades gerenciais sejam incorporados como categorias ao modelo teórico tomado como referência.

Palavras-chave: Implementação de Estratégia de Marketing; Indústrias Criativas; Indústria de Jogos Eletrônicos; Criatividade; Inovação.

\section{MARKETING STRATEGY IMPLEMENTATION PROCESS IN THE CREATIVE INDUSTRY OF VIDEO GAMES}

\begin{abstract}
This article contributes to the understanding of marketing strategy process when it presents the organizational and human factors that support the processes of implementation, identified in a qualitative study conducted in the creative industry of video game development. The research, a case study applied to four video and computer game companies was based on the Sashittal and Jassawalla (2001) marketing strategic model, and on the concepts of the creative behavior and innovation in organizations proposed by Amabile (1997). The analysis suggests that the marketing strategy implementation is anchored in innovative administrative process, creative skills and the adoption of modern control technologies. It was observed that a vision that associates production, process, the market orientation and the delivery of value-adding is essential for the implementation of strategies in creative and innovative organizational structures. The research contributes to the marketing strategy implementation studies in creative and innovative environments under the approach of smaller organizations. It also contributes with the marketing strategy theory when it suggests that the analysis of the process, the control and the management skills be included as categories into the theoretical model in future investigations.
\end{abstract}

Keywords: Marketing Strategy Implementation Process; Creative Industries; Video And Computer Games Industry; Creativity, Innovation. 
PROCESOS DE APLICACIÓN DE ESTRATEGIAS DE MARKETING EN LA INDUSTRIA CREATIVA DE VIDEO JUEGOS

\section{RESUMEN}

Este artículo contribuye a la comprensión del proceso de la estrategia de marketing, cuando se presentan los factores organizacionales y humanos que impulsan procesos de aplicación identificados en estudio cualitativo realizado en la industria creativa desarrolladora de videojuegos. La investigación, un estudio de casos aplicados a cuatro oficinas de videojuegos, se basó en el modelo de aplicación de la estrategia de marketing de Sashittal y Jassawalla (2001) y en los conceptos de la conducta creativa y de la innovación en las organizaciones propuestos por Amabile (1997). El análisis sugiere que la aplicación de la estrategia de marketing está anclada en patrones de gestión innovadores, en la capacidad creativa además de la adopción de técnicas modernas de controles. Se observó que una visión que asocia la producción, el proceso, la orientación al mercado y la entrega de valor es esencial para la aplicación de estrategias de marketing en las estructuras organizacionales creativas e innovadoras. La investigación contribuye a los estudios de aplicación de la estrategia de marketing en ambientes creativos e innovadores bajo la perspectiva de las pequeñas empresas y también contribuye con la teoría de la estrategia de marketing cuando sugiere que en futuras investigaciones el análisis del proceso, el control y las habilidades de gestión sean incluidos como categorías en el modelo teórico elegido.

Palabras-clave: Aplicación de la Estrategia de Marketing; Las Industrias Creativas; Industria Electrónica Juegos; Creatividad; Innovación. 
Processos de Implementação de Estratégias de Marketing na Indústria Criativa de Jogos Eletrônicos

\section{INTRODUÇÃO}

A literatura de estratégia tem sido pródiga em apontar as variáveis essenciais para que a execução de planos, processos e as escolhas gerenciais sejam eficazes na etapa de implementação e façam a estratégia funcionar de forma satisfatória. Mintzberg, Ahlstrand e Lampel (2000), Hrebiniak (2006) e Mintzberg, Lampel, Quinn e Ghoshal (2006), por exemplo, quando se referem a processos de estratégia de maneira geral, chamam atenção para o ambiente externo e para o interno como importantes requisitos de análise e ainda destacam a estrutura e o design organizacional como variáveis influentes sobre a execução. Piercy (1998, 2005), Bonoma e Crittenden (1988), Menon, Bharadway, Adidam e Edison (1999), Noble e Mokwa (1999), Sashittal e Jassawalla (2001), Toaldo (2004), Olson, Slater e Hult (2005) e Slater, Hult e Olson (2010) corroborando com a perspectiva desses autores, enfatizam que alguns componentes da própria organização ou de seu ambiente tarefa podem interagir também durante a implementação de estratégias com propósito de um posicionamento mais efetivo, com entrega de valor e foco na manutenção de vantagens competitivas.

Em qualquer circunstância, é inquestionável a importância de se analisar a contribuição desses estudos para o conhecimento geral da teoria de estratégia de marketing. No entanto, a despeito dos tradicionais setores investigados, geralmente focados em grandes organizações complexas, e, nas condições atuais de tecnologias transformadoras, outras investigações poderiam ser realizadas a fim de se identificar reais variáveis ou fatores que ancoram a execução de estratégias de setores inovadores. Ratificando essa perspectiva, o Marketing Science Institute (MSI), referência para muitos pesquisadores em marketing, apontava algumas prioridades de temas em seu guia relativo ao período 2008-2010, dentre os quais se destacam estratégia de marketing, novas mídias e inovação, considerando não só novos produtos, mas questões de design, criatividade e impacto de novas tecnologias nos processos produtivos (MSI, 2008). Nesse contexto, como possível objeto de investigação, poderiam ser inseridas as chamadas indústrias criativas, um conceito emergente de atividade econômica que congrega segmentos produtivos, geralmente formados de pequenas empresas, que desenvolvem atividades com foco na criatividade e na inovação (Flew, 2002; Unctad, 2008; Jeffcutt, 2009; Reis, 2007, 2008).

Como objeto de estudo, as indústrias criativas correspondem a um setor que tem sido pouco explorado em investigações acadêmicas de marketing, conforme levantamento feito nos anos 2009 e 2010 nas bases de dados da área, Ebsco e ProQuest, em que se utilizou como parâmetros de pesquisa os seguintes assuntos: indústrias criativas, criatividade e inovação, e considerou-se como 
fontes de consulta os mais expressivos periódicos acadêmicos, as revistas, os jornais, além de dissertações e teses disponibilizadas. Destaca-se que é pressuposto que as vantagens competitivas das indústrias criativas estejam principalmente no uso de seus fatores humanos, nas suas habilidades e na geração das ideias (Flew, 2002; Jeffcutt, 2009). Além disso, em razão da dinâmica e complexidade do mercado, empresas incluídas neste perfil são impactadas de forma direta em seus processos, nas escolhas estratégicas e, principalmente, na sua vantagem competitiva, quando necessitam responder, de forma ágil e flexível, às novas demandas. Lawrence e Philips (2009, p. 18) advogam que

muitas das indústrias criativas são vítimas das mudanças abruptas no gosto. A sua habilidade de administrar em um mundo de incerteza e de significados extremamente complexos é sua principal vantagem competitiva. Mas que modos de se organizar são mais apropriados, que técnicas administrativas são mais efetivas e que questões básicas enfrentam as organizações intensivas em símbolos são questões que devem ser ainda investigadas por pesquisadores de gestão e organização.

Essas abordagens direcionaram para algumas questões de estratégia de marketing que instigaram a exploração com maior profundidade do assunto: como pequenas empresas que trabalham com capital intelectual executam suas estratégias de marketing? Como se caracterizam os principais fatores que suportam os processos de implementação de estratégias em ambientes criativos? De acordo com alguns autores é pressuposto encontrar particularidades nos processos de implementação nesses segmentos, pois, tais organizações, apresentam níveis crescentes de personalização de produtos e serviços (Flew, 2002; R. E. Miles, Mathews, Miles, \& Coleman, 2006), recebem interferência de amplas e imprevisíveis preferências de clientes (Voss \& Voss, 2000) e tendem a ser mais rápidos nas respostas ao mercado, adequando continuamente seu processo de entrega de valor.

Concomitantemente à proposta de se focar em um ambiente intensivo em criatividade e inovação como objeto de estudo, tomou-se o ponto de vista de Sashittal \& Jassawala, (2001), Heribiniak (2006), Noble e Mokwa (1999) quando comentam que o processo de execução tem sido pouco explorado em estudos empíricos de estratégia de marketing e, de acordo com Varadarajan (2010), Toaldo e Luce (2006), a implementação é tema que na literatura tem se apresentado com carência de aprofundamento. Essas diversas perspectivas, combinadas e inter-relacionadas, endossaram a justificativa de se estudar a indústria criativa, objetivando explorar, através de uma pesquisa qualitativa, o processo de estratégia de marketing, especificamente no que se refere à execução, em pequenas empresas que transformam arte, criatividade e tecnologia em valor de mercado. A pesquisa, um estudo de casos múltiplos, contemplou o processo de implementação de 
Processos de Implementação de Estratégias de Marketing na Indústria Criativa de Jogos Eletrônicos

estratégias de marketing em quatro estúdios brasileiros de criação de jogos eletrônicos, com base na abordagem de Sashittal e Jassawalla (2001) a respeito de implementação de estratégias em pequenas e médias empresas pertencentes a segmentos inovadores, associada aos conceitos de comportamento criativo e inovação nas organizações de Amabile (1997). O estudo contribui para com a pesquisa de estratégia de marketing de forma específica no que se refere à averiguação dos processos de execução, ao apresentar em seus resultados os principais fatores que ancoram a implementação de estratégias em ambientes criativos, considerando as questões organizacionais e humanas a eles relacionadas, e ao demonstrar os requisitos essenciais para sua efetividade nesses ambientes.

Este artigo sintetiza os resultados obtidos no estudo e relata as contribuições da pesquisa às proposições teóricas referenciadas no modelo de Sashittal \& Jassawala (2001) ao dar ênfase aos processos, aos controles e às habilidades gerenciais como elementos influentes na efetividade da estratégia nestes ambientes. O texto contempla em sua estrutura essa introdução, que descreve o objetivo do estudo e outras cinco partes, a saber: a referência teórica e empírica que deu suporte à investigação, os procedimentos metodológicos utilizados, a apresentação e análise dos dados obtidos e a discussão dos resultados alcançados. A última parte apresenta as considerações finais, incluindo limitações, sugestões para pesquisas futuras e as contribuições teóricas que se originaram da análise da pesquisa em questão.

\section{REFERÊNCIA TEÓRICA E EMPÍRICA - ESTRATÉGIA E ESTRATÉgIA DE MARKETING}

Na revisão da literatura buscou-se o entendimento conceitual dos tópicos que serviram de apoio à resposta do problema identificado. Das várias correntes e escolas de estratégia, principalmente dos estudos realizados por Ansoff (1977, 1990), Mintzberg (2000, 2004), Mintzberg et al. (2000), Whittington (1996), Mintzberg (2006a, 2006b, 2006c), Mintzberg et al. (2006), Andrews (2006), Porter (1986, 1999), foram tomadas referências para identificação dos conceitos de estratégia no nível organizacional. Do pensamento de P. R. Varadarajan e Yadav (2002), R. Varadarajan (2010), Hrebiniak (1990, 2006), Wensley (2005) e Day (1992, 1994), foram extraídos conceitos relacionados à implementação de estratégia já no nível tático. E, complementando a revisão, ao analisar a estratégia pelo enfoque funcional, foram estudados modelos ou estruturas do processo de implementação de Piercy (1998, 2005), com seu Modelo de Dimensões de Processos e foco em processos e entrega de valor; de Aaker (2001), a estrutura de análise de organizações com 
foco em componentes organizacionais; de Noble e Mokwa (1999), o Modelo de Implementação, no qual se destaca o papel da gerência no processo e, finalmente, de Sashittal e Jassawalla (2001), o Modelo Processo de Planejamento e Implementação em Pequenas e Médias empresas, que contempla as forças que moldam as empresas em resposta ao movimento dos mercados.

Além da perspectiva desses autores, outros postulados foram importantes para a compreensão dos fatores e variáveis que envolvem o processo de implementação. As idéias de Menon et al. (1999), Toaldo (2004), Bonoma e Crittenden (1988), Céspedes e Piercy (1996), Olson et al. (2005), Slater e Olson (2001), Slater et al. (2010), Toaldo, Jotz e Luce (2008), Voss e Voss (2000) serviram de apoio para ampliar o entendimento dos elementos elencados no Modelo Processo de Planejamento e Implementação de Sashittal e Jassawalla (2001), tomado em sua estrutura como suporte para o desenvolvimento da investigação.

De Bonoma e Crittenden (1988) destacam-se as contribuições relacionadas às variáveis estruturais - nas quais estão incluídas as funções de marketing, os sistemas de controle e as diretrizes e políticas, e os fatores comportamentais - que incluem as habilidades dos gestores em negociar, alocar recursos e em desenvolver uma estrutura informal e flexível que suporte o processo de implementação. De Noble e Mokwa (1999), Aaker (2001) e Piercy (2005), foi possível obter a identificação, descrição e classificação de certas variáveis estruturais e comportamentais, definidas como fatores influenciadores e também de suporte à entrega de valor no processo de implementação de estratégias de marketing nas organizações.

Pautando-se nessas e em outras abordagens presentes na literatura e procurando ampliar seu conceito a partir da perspectiva que considera amplitude organizacional e não somente a função de marketing no processo de implementação, Sashittal e Jassawalla (2001) descreveram como o fenômeno se desdobra na prática, indicando variáveis e fatores importantes relacionados às questões humanas e organizacionais que o suportam. Essas variáveis foram inseridas em uma estrutura esquemática denominada Modelo de Processo de Planejamento e Implementação de Estratégia de Marketing em Pequenas e Médias Empresas Industriais, posteriormente validada pelos pesquisadores em uma investigação.

Constituído a partir de amplo referencial teórico, o Modelo de Sashittal e Jassawalla (2001), conforme apresentado na Figura 1, está estruturado por quatro categorias que agrupam variáveis observadas como influentes sobre o processo de implementação de marketing em pequenas empresas.

A categoria Antecedentes Contextuais considera as forças ambientais externas, as escolhas no nível estratégico e o design organizacional ao analisar os padrões gerais de comportamento da 
Processos de Implementação de Estratégias de Marketing na Indústria Criativa de Jogos Eletrônicos empresa no mercado. A categoria Influências do Nível Operacional é explicada pelos eventos diários do ambiente tarefa e pelas escolhas no nível operacional, que correspondem às decisões com relação ao composto mercadológico e respostas de curto prazo a outras interferências emergenciais. Já a categoria, Escolhas Gerenciais, é resultante da combinação de habilidades e escolhas, integrando empresa e ambiente, e está relacionada à interdependência entre planejadores e implementadores, às habilidades estratégicas e também às respostas da empresa às forças do mercado. Por fim, Sashittal e Jassawalla (2001) demonstram que a categoria Resultados de Processos de Estratégia de Marketing se vincula ao desempenho associado a clientes, produtos e mercados e ao desempenho da organização, com relação aos aspectos psicossociais, considerando satisfação dos funcionários e segurança no trabalho.

Figura 1- Modelo Processo de Planejamento e Implementação de Estratégia de Marketing em Pequenas e Médias Empresas Industriais

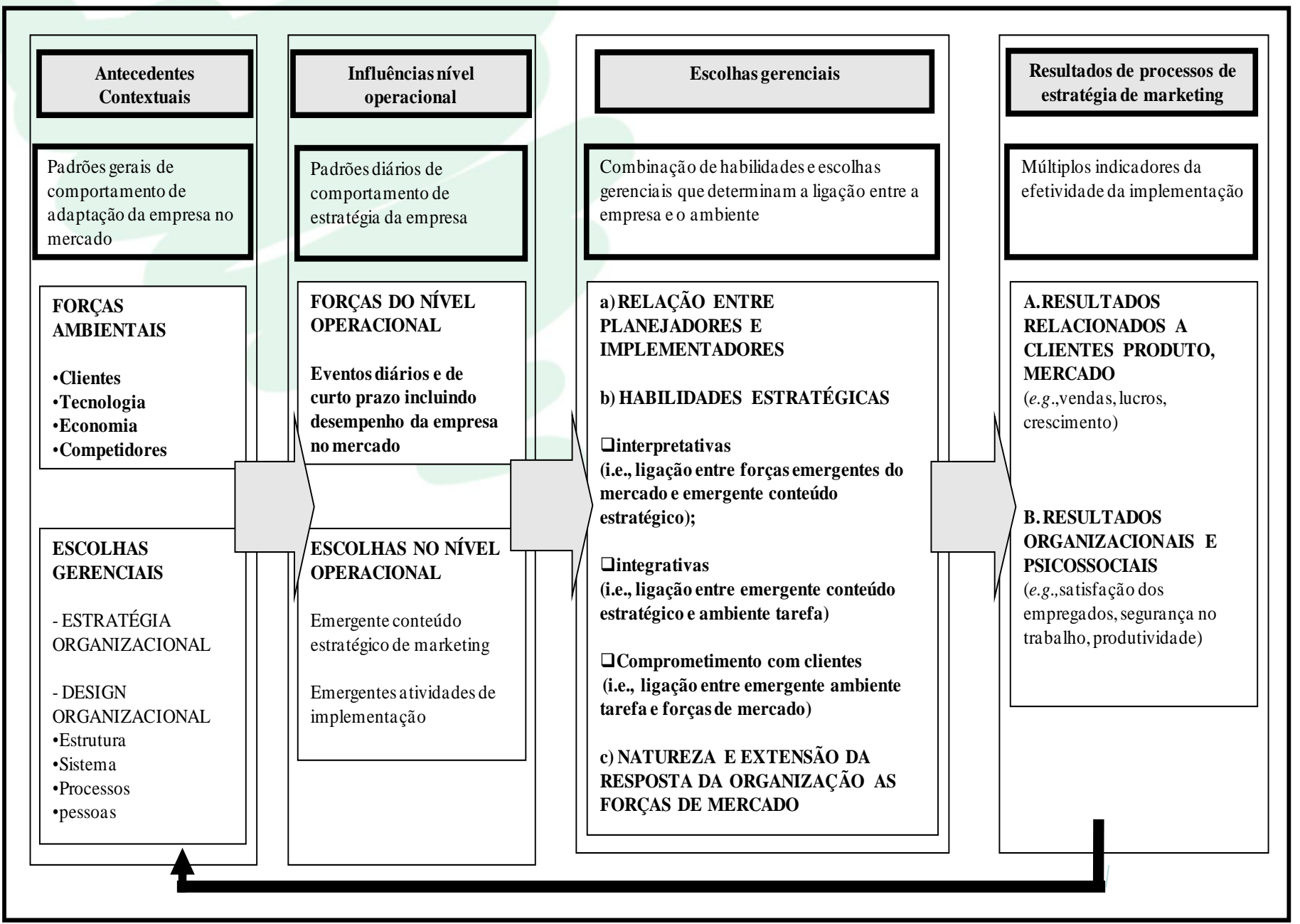

Fonte: Adaptado de Sashittal, H. C., \& Jassawalla, A. R. (2001). Marketing implementation in smaller organizations: definition, framework, and propositional inventory (p. 56, tradução nossa). Journal of the Academy of Marketing Science, 29(1), 50-69. doi: 10.1177/0092070301291004 
Muito embora os pesquisadores não tenham tido pretensões de generalização quanto aos elementos definidos e apontados em seu modelo, as implicações resultantes da análise realizada são bastante abrangentes. Além de apontarem que a interação dos processos de planejamento e implementação afeta os resultados estratégicos, os pesquisadores deram foco à ligação entre estratégias deliberadas e emergentes, ao entendimento das reações automáticas e inesperadas, comuns ao contexto das pequenas empresas e, de forma bastante contundente, enfatizaram o papel dos gestores no processo de implementação. Tomando o modelo sob essa perspectiva e pautando-o na investigação realizada em ambientes criativos e inovadores, foi possível se fazer a análise de outras relações de elementos nele contidos. Os resultados da investigação nos estúdios de criação de jogos eletrônicos corroboram com a proposição teórica desses autores e ao mesmo tempo sugerem o incremento de novos conceitos à estrutura proposta.

Para complementar o referencial sobre implementação de estratégias de marketing, na subseção seguinte são apresentados conceitos de Indústrias Criativas, com considerações sobre a indústria desenvolvedora de jogos eletrônicos, tomada como nível de análise da investigação. Adicionalmente são demonstrados conceitos relacionados à criatividade e à inovação, variáveis inseridas no estudo na condição de coadjuvantes.

\subsection{INDÚSTRIAS CRIATIVAS - ORIGENS, A INDÚSTRIA DESENVOLVEDORA DE JOGOS ELETRÔNICOS, CRIATIVIDADE E INOVAÇÃO}

O crescente e complexo volume de conhecimentos desenvolvidos, traduzidos em design, criatividade, tecnologia e inovação, e sua acelerada incorporação a bens e serviços, fazem parte de um fenômeno conhecido como economia da criatividade. Essa economia em contínuo processo de expansão é resultado de um conjunto de atividades identificadas em setores produtores ou prestadores de serviços denominados Indústrias Criativas, que chamam atenção por serem veículos de identidade cultural, representativos da sociedade baseada no conhecimento, e por estarem acima da média de crescimento e criação de postos de trabalho (Bendassolli, Wood, Kirschbaum, \& Cunha, 2009; Flew, 2002; United Nations Educational, Scientific and Cultural Organization [UNESCO], Global Alliance for Cultural Divercity, 2006). São consideradas indústrias criativas segmentos que:

têm sua origem na criatividade, habilidade e talento individuais, têm potencial para a criação de renda e empregos por meio da geração e exploração da propriedade intelectual ... e incluem: propaganda, arquitetura, mercados de arte e antiguidades, artesanato, design, moda, filme e vídeo, software de lazer, artes performáticas, edição, jogos de computador, serviço de televisão e rádio (Department for Culture, Media and Sport [DCMS], 2001, p. 5, tradução nossa). 
Processos de Implementação de Estratégias de Marketing na Indústria Criativa de Jogos Eletrônicos

Esse conceito dado pelo governo inglês parece ser o mais divulgado em todo mundo e pela ótica institucional foi replicado para diversos países, inclusive para o Brasil (Reis, 2007, 2008). De maneira complementar, em direção a uma definição mais clara e que aproxima a produção criativa com sentido de mercado, a Conferência das Nações Unidas para o Comércio e Desenvolvimento (Unctad) classifica as Indústrias Criativas em 4 grandes grupos: patrimônio cultural, artes, mídia e criações funcionais (Unctad, 2008). Segundo a instituição, neste último grupo está inserido o subgrupo das empresas desenvolvedoras de jogos eletrônicos ou digitais, conhecidos como estúdios de criação e que foram considerados como unidade de análise da investigação.

Os estúdios de desenvolvimento de jogos eletrônicos fazem parte da cadeia produtiva que inclui publicadores, atividades de promoção, publicidade e distribuição, realizadas pelos distribuidores e empresas desenvolvedoras de plataformas, de sistemas integradores ou de processamento de jogos (I. Miles \& Green, 2008). De acordo com Tschang e Vang (2008) os jogos eletrônicos são formados por três aspectos principais interligados: design, tecnologia e arte e toda indústria desenvolvedora se assenta em uma força de trabalho técnica e criativa, formada por especialistas, de quem normalmente é exigido equilíbrio entre criatividade e racionalização (Cohendet \& Simon, 2007; Perucia, Balestrin, \& Verschoore, 2009).

Além das características criativas, o jogo eletrônico pode ser analisado como resultado de um projeto industrial complexo, administrado debaixo de rígidas condições de eficiência. DyerWitherford e Sharman (2005) postulam que seu desenvolvimento é demorado, caro e arriscado, e que um projeto de jogo está sujeito a pressões financeiras e de tempo e ainda necessita alcançar mercado em um ambiente altamente competitivo. Para Cohendet e Simon (2007), gestores dos estúdios devem aproveitar a entrega de valor baseada nos valores artísticos, criativos e inovadores para torná-los sucesso comercial, como uma compensação ou como uma maneira de se contrapor às restrições econômicas próprias do entretenimento de massa, contexto do qual faz parte a maioria dos produtos desse tipo de mídia.

Analisando-se as explanações de Cohendet e Simon (2007) sobre aspectos administrativos dos estúdios, assim como as informações de Tschang e Vang (2008) e Dyer-Witherford e Sharman (2005) sobre os aspectos de produção dos jogos, que incluem principalmente criatividade e inovação, tomou-se como premissa que essas variáveis fossem incluídas na investigação para observação de sua influência no processo de implementação das estratégias de marketing. Essa análise se apoiou na perspectiva de Amabile (1997), extraída de sua Teoria Componencial da Criatividade e Inovação em organizações, na qual a pesquisadora define a criatividade como resultante de três elementos complementares e que se integram no ambiente organizacional: 
expertise, habilidade para o pensar criativo (raciocínio criativo) e motivação para a execução das tarefas.

A estrutura proposta pela pesquisadora, representada na Figura 2, demonstra a inter-relação entre a criatividade e a inovação no ambiente de trabalho e considera o impacto de uma sobre a outra. Deste modo, busca-se conectar os demais elementos indicados em sua teoria, na descrição sobre a categoria orientação à inovação, Amabile (1997) aponta como variáveis de análise a motivação organizacional para inovar, os recursos envolvidos e as práticas de gestão inovadoras, mostrando, da mesma forma, a integração e complementaridade entre eles.

Figura 2 - Teoria Componencial da Criatividade e da Inovação Organizacional - Impacto do Ambiente Organizacional sobre a criatividade

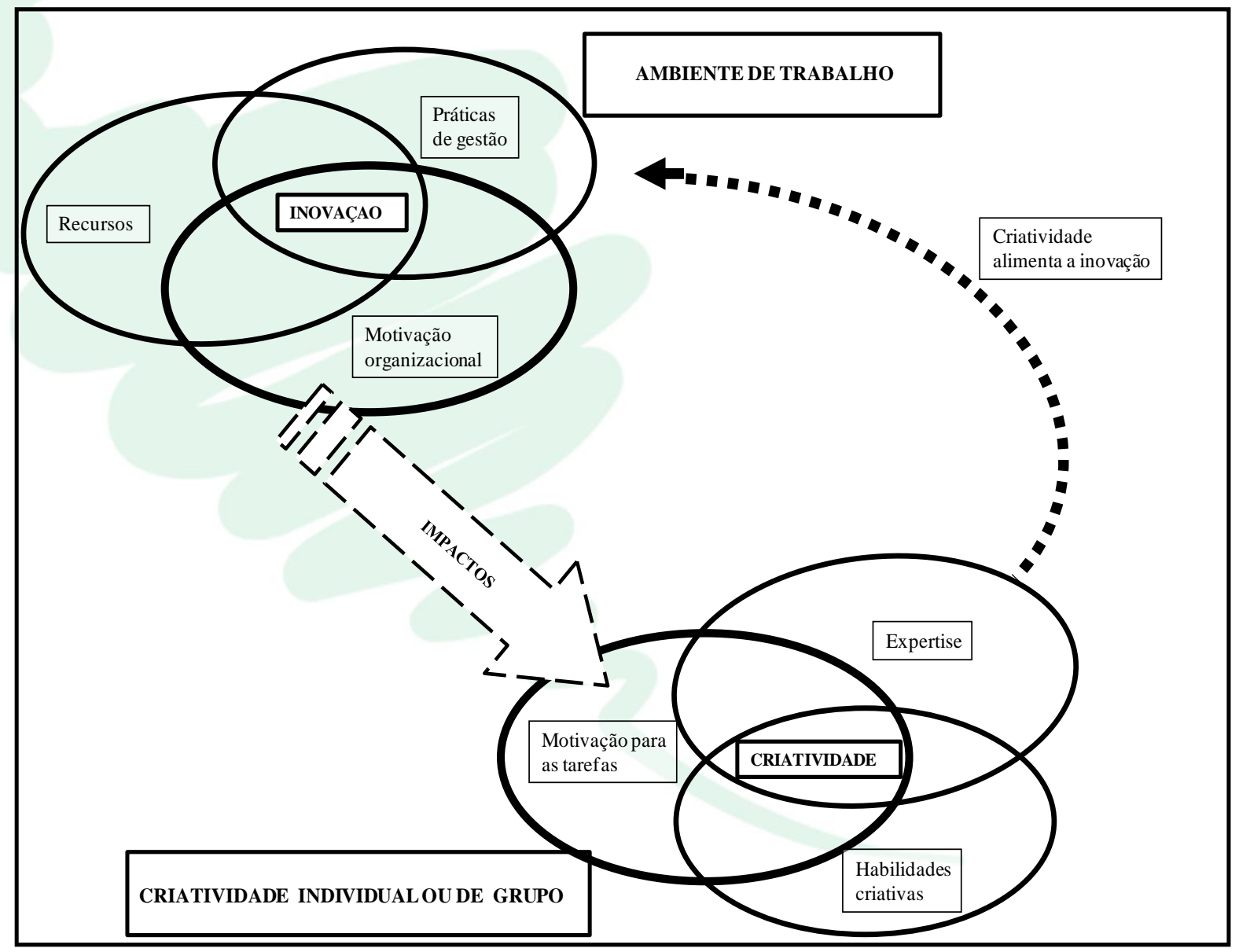

Fonte: Adaptado de Amabile, T. M. (1997). Motivating creativity in organizations: on doing what you Love and loving what you do (p. 53). California Management Review, 40(1), 39-58. 
Processos de Implementação de Estratégias de Marketing na Indústria Criativa de Jogos Eletrônicos

Após explanação das perspectivas selecionadas sobre implementação de estratégia de marketing, dos conceitos de indústrias criativas e de criatividade e inovação, a seguir são apresentados os procedimentos metodológicos utilizados no estudo. Na sequência são descritos os dados obtidos e a análise realizada sobre os fatores que ancoram o processo de implementação de marketing na indústria criativa desenvolvedora de jogos eletrônicos.

\section{PROCEDIMENTOS METODOLÓGICOS}

Embora o tema estratégia de marketing não seja novo não foram encontrados na literatura estudos semelhantes com a temática implementação de estratégia que tivessem como objeto de investigação as indústrias criativas, e de forma particular, os estúdios de criação de jogos eletrônicos. Considerando a complexidade do tema e a necessidade de compreendê-lo em profundidade, optou-se por uma investigação qualitativa baseada em estudo de casos múltiplos, com abordagem exploratória em razão da possibilidade de se obter maior familiaridade com o assunto. A investigação foi realizada em quatro estúdios brasileiros, identificados na análise como Estúdio Alfa (EA), Estúdio Beta (EB), Estúdio Gama (EG) e Estúdio Delta (ED). Estes estúdios foram escolhidos dentre os 42 formais existentes, de acordo com a Associação Brasileira das Desenvolvedoras de Jogos Eletrônicos (Abragames), afiliados a essa e que foram selecionados pelo número de empregados no processo produtivo e pela localização nas regiões Sul e Sudeste. A opção por casos múltiplos se adapta à perspectiva de Yin (2005) e também de Gil (2009), que apontam ser técnica favorável neste tipo de investigação exploratória, por haver possibilidade de extração de conclusões analíticas quando da análise conjunta, além de identificação de possíveis fatores que o influenciam ou são por ele influenciados, quando se tem uma visão global do problema.

Os conceitos extraídos das estruturas propostas por Sashittal e Jassawalla (2001) e por Amabile (1997) foram tomados como base e fundamentação das categorias de análise e permitiram ancorar o escopo do estudo de casos, estabelecendo suas fronteiras na pesquisa. A possibilidade de se aplicar conhecimento adquirido e validado sobre o processo de implementação de estratégias de marketing em pequenas empresas, como é o caso da grande maioria das indústrias criativas (I. Miles \& Green, 2008; Jeffcutt, 2009), teve grande importância sobre a escolha do modelo de Sashittal e Jassawalla (2001). A estrutura desses pesquisadores se mostrou adequada e suficiente para os propósitos do estudo, fato que levou a sua escolha como base teórico-empírica da investigação. Complementarmente, os conceitos de criatividade e inovação extraídos da estrutura de 
Amabile (1997), validados pela pesquisadora em ambientes de alta tecnologia, foram incorporados ao estudo por ambos se fazerem presentes nas indústrias criativas, conforme atestam Flew (2002), Jaguaribe (2008), Reis (2007, 2008), Bendassolli et al., (2009) e os organismos Unesco (2006) e Unctad (2008), quando apontam que essas variáveis são matérias primas dos segmentos nelas inseridos.

Para respaldar a coleta de informações adotou-se como base o protocolo de investigação utilizado por Sashittal e Jassawalla (2001), adaptado para o estudo, resultando em um instrumento com questões orientativas para a realização de entrevistas. A investigação foi instrumentalizada em sete entrevistas gravadas, posteriormente tratadas e analisadas, realizadas com os principais executivos e gerentes de produção dos estúdios, caracterizados e codificados conforme Figura 3. Para garantir solidez à investigação, o assunto foi explorado sob diversos pontos de vista com os respondentes. E ainda, a observação direta do comportamento dos entrevistados e envolvidos no ambiente das empresas, além da observação do método de trabalho e emprego dos recursos, permitiram verificar a influência da criatividade e da inovação na tomada de decisões.

Figura 3 - Características dos estúdios e entrevistados

\begin{tabular}{|c|c|c|c|}
\hline $\begin{array}{l}\text { ESTUDIO } \\
\text { (unidade de análise) }\end{array}$ & CARACTERISTICAS GERAIS (produção/serviços) & $\begin{array}{l}\text { ENTREVISTADO } \\
\text { (unidade de observação) }\end{array}$ & Cargo/Função \\
\hline \multirow{2}{*}{$\begin{array}{l}\text { ALPHA (EA) Ano: } 2006 \\
65 \text { profissionais }\end{array}$} & \multirow{2}{*}{$\begin{array}{l}\text { Jogos para publicadores e distribuidores externos } \\
\text { Estratégia:foco no serviço/segmento estreito de mercado. }\end{array}$} & Gestor Alphal & Diretor /Adm. Comercial \\
\hline & & Gestor Alpha2 (g2EA) & Diretor / Produção \\
\hline $\begin{array}{l}\text { BETA (EB) Ano: } 2003 \\
15 \text { profissionais }\end{array}$ & $\begin{array}{l}\text { Jogos massivos baseados na web (portal próprio). } \\
\text { Estratégia: foco no serviço/ mercado amplo. }\end{array}$ & Gestor Beta $\quad$ (gEB) & Diretor Des. Produtos \\
\hline \multirow{3}{*}{$\begin{array}{l}\text { GAMMA (EG) Ano: } 2002 \\
20 \text { profissionais }\end{array}$} & \multirow{3}{*}{$\begin{array}{l}\text { Jogos empresariais (publicidade/ treinamento) } \\
\text { Estratégia: mercado específico/ oferta de vários serviços. }\end{array}$} & Gestor Gammal (g1EG) & Diretor Adm.Comercial \\
\hline & & Gestor Gamma2 (g2EG) & Diretor/Arte e Design \\
\hline & & Gestor Gamma3 (g3EG) & Diretor/Ger. Projetos \\
\hline $\begin{array}{l}\text { DELTA (ED) Ano: } 2003 \\
15 \text { profissionais }\end{array}$ & $\begin{array}{l}\text { Jogos empresariais (educação); jg para mercado externo. } \\
\text { Estratégia: foco no serviço/ mercado específico }\end{array}$ & Gestor Delta & Diretor /Adm. Des. Produtos \\
\hline
\end{tabular}

Fonte: Estruturado a partir do material empírico da investigação 
Processos de Implementação de Estratégias de Marketing na Indústria Criativa de Jogos Eletrônicos

\subsection{VARIÁVEIS OBSERVADAS, SELEÇÃO E TRATAMENTO DO MATERIAL EMPÍRICO}

As variáveis identificadas nos dois modelos referenciados foram agrupadas em 5 categorias de análise assim denominadas: antecedentes contextuais, influenciadores do nível operacional, escolhas gerenciais, indicadores de resultados e influência da criatividade e da inovação no processo de implementação de estratégias de marketing, tomadas como facilitadores na criação de um trabalho científico objetivo e coerente. Para o tratamento do material empírico foram utilizados alguns procedimentos de análise de conteúdo defendidos por Bardin (2002). Os dados foram preparados e organizados de forma a permitir a identificação de temas enfatizados pelos entrevistados, que depois foram codificados, agrupados, rotulados e integrados às categorias, conforme definidas e denominadas por Sashittal e Jassawalla (2001) e Amabile (1997). Para a convergência de informações utilizou-se o processo de triangulação de fonte de dados obtidos antes, durante e depois das entrevistas (Martins, 2008), apoiado em critérios de qualidade, na sistematização e na seleção de padrões semelhantes entre as informações e entre os casos. $\mathrm{O}$ material empírico coletado permitiu a apreciação dos quatro casos isoladamente assim como foi possível também a análise de fatores recorrentes que caracterizam e descrevem o comportamento dessa indústria criativa com relação aos processos de implementação de estratégias de marketing.

\section{APRESENTAÇÃO E ANÁLISE DOS DADOS}

A análise dos dados da pesquisa permitiu estratificar e sintetizar as observações julgadas mais significativas e alguns elementos foram identificados como comuns às empresas. Esses elementos, por análise sistematizada, podem ser considerados prováveis a maioria dos estúdios e, por inferência, podem ser tomados como concernentes à indústria criativa desenvolvedora de jogos eletrônicos. Alguns pontos da análise são destacados a seguir.

\subsection{ANTECEDENTES CONTEXTUAIS E INFLUENCIADORES DO NÍVEL OPERACIONAL}

Essas duas categorias estão relacionadas às forças ambientais externas, às escolhas com relação a objetivos, mercados-alvo e aplicação dos recursos. Na análise dos fatores influentes sobre as decisões operacionais destaca-se a variável clientes que "apresentam alto nível de exigência 
quanto a qualidade, criatividade e custos" (g1EA), no caso de clientes publicadores ou de clientes usuários finais que sugerem melhorias na forma de jogar ou opinam sobre o desenvolvimento do jogo: "sempre fazemos teste de conceito com o publico final, porque é uma maneira de minimizarmos nossos riscos" (gEG1).

A tecnologia, outra variável influente, embora seja elemento chave nas decisões de desenvolvimento dos jogos e na consolidação do próprio negócio, parece não atuar isoladamente, mas em conjunto com os objetivos estratégicos, ou seja, emprego de recursos e decisões do composto de marketing. De acordo com a posição dos estúdios EA, EG e ED, o diferencial não está no emprego apenas de recursos de última geração, mas nas soluções que os estúdios apresentam para os clientes a partir daquilo que eles querem: "no atendimento às necessidades do cliente, a tecnologia que será usada é uma ferramenta e não um direcionador do projeto.(...) $O$ diferencial está no conceito de seu uso e não na própria tecnologia”(g1EA) E ainda: “A tecnologia para nós é meio e não fim. Ela é ferramenta e nosso investimento é no sentido de escolher a ferramenta mais barata, mais adequada e mais eficiente." (gED). Para EB, no entanto, o emprego e o desenvolvimento interno e intenso de inteligência artificial de ponta, é recurso imprescindível para estar à frente da concorrência: "A tecnologia muda de uma hora para outra. Aqui [no estúdio] ela é um investimento da empresa na própria empresa” (gEB).

Referindo-se às escolhas estratégicas no emprego dos recursos, foram considerados como ativos estratégicos as pessoas, sua criatividade, a capacitação e a autonomia (EA), o controle sobre os processos para minimizar riscos vindos de mudanças contingenciais (EG, ED, EA) e a tecnologia de ponta para respostas mais rápidas às demandas de mercado (EB). A Tabela 1 resume essa análise e apresenta outras informações sobre as forças do nível estratégico mais influentes nas decisões de implementação por parte dos estúdios. Paralelamente, no ambiente tarefa dos estúdios foram analisados os fatores vinculados às escolhas e decisões do composto de marketing e o design organizacional, considerando a sua adequação para a efetividade dos processos produtivos. 
Processos de Implementação de Estratégias de Marketing na Indústria Criativa de Jogos Eletrônicos

Tabela 1 - Antecedentes Contextuais Influentes: Forças do Nível Estratégico

\begin{tabular}{|c|c|c|c|c|}
\hline \multicolumn{5}{|c|}{ ANTECEDENTES CONTEXTUAIS INFLUENTES NAS DECISÕES ESTRATÉGICAS } \\
\hline & Estúdio Alpha (EA) & Estúdio Beta (EB) & Estúdio Gamma (EG) & Estúdio Delta (ED) \\
\hline 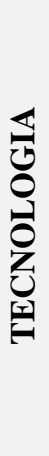 & $\begin{array}{l}\text { Como solução técnica: } \\
\text { influencia na alocação de } \\
\text { recursos e investimentos } \\
\text { (melhor custo benefício } \\
\text { para o cliente). } \\
\text { No desenvolvimento: } \\
\text { adoção de tecnologia já } \\
\text { utilizada, } \\
\text { desenvolvimento próprio } \\
\text { ou aquisição }\end{array}$ & $\begin{array}{l}\text { Como recurso } \\
\text { principal: influencia } \\
\text { sobre estratégia de } \\
\text { desenvolvimento } \\
\text { (tecnologia de } \\
\text { vanguarda). } \\
\text { No desenvolvimento } \\
\text { dos jogos: tecnologia } \\
\text { própria e uso de } \\
\text { inteligência artificial }\end{array}$ & $\begin{array}{c}\text { Como solução técnica:- } \\
\text { influencia sobre a } \\
\text { inovação do jogo ( } \\
\text { formas alternativas de } \\
\text { jogar + narrativa). } \\
\text { No desenvolvimento: } \\
\text { adoção de tecnologia já } \\
\text { utilizada, } \\
\text { desenvolvimento próprio } \\
\text { ou aquisição }\end{array}$ & $\begin{array}{l}\text { Como solução técnica: } \\
\text { influencia na alocação de } \\
\text { recursos e investimentos } \\
\text { (melhor custo benefício } \\
\text { para o cliente). } \\
\text { No desenvolvimento: } \\
\text { adoçao de tecnologia já } \\
\text { utilizada, } \\
\text { desenvolvimento próprio } \\
\text { ou aquisição }\end{array}$ \\
\hline 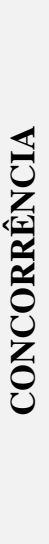 & $\begin{array}{l}\text { Mecanismos de defesa: } \\
\text { adoção de práticas de } \\
\text { gestão de estúdios } \\
\text { internacionais e } \\
\text { processos operacionais } \\
\text { originários de técnicas de } \\
\text { gerenciamento de } \\
\text { projetos. Adoçao de } \\
\text { metodologia de controles. } \\
\text { Pirataria: problema do } \\
\text { publicador. }\end{array}$ & $\begin{array}{c}\text { Mecanismos de defesa: } \\
\text { Tomar como referencia } \\
\text { os próprios concorrentes } \\
\text { e seus sucessos e falhas } \\
\text { para melhorar } \\
\text { funcionalidades e outros } \\
\text { aspectos do } \\
\text { desenvolvimento dos } \\
\text { jogos. Pirataria: } \\
\text { convivência inevitável } \\
\text { /sem criar mecanismos } \\
\text { de bloqueio. }\end{array}$ & $\begin{array}{c}\text { Mecanismo de defesa: } \\
\text { monitoramento. } \\
\text { Concorrencia pouco } \\
\text { influente sobre as } \\
\text { decisões de } \\
\text { desenvolvimento de } \\
\text { produtos sob demanda. } \\
\text { Pirataria: combate com } \\
\text { decisão estratégica: mais } \\
\text { jogos customizados e } \\
\text { menos jogos de } \\
\text { entretenimento (mais } \\
\text { vulneráveis). }\end{array}$ & $\begin{array}{l}\text { Mecanismos de defesa: } \\
\text { adoção de práticas de } \\
\text { gestão de estúdios } \\
\text { internacionais e processos } \\
\text { operacionais originários } \\
\text { de técnicas de } \\
\text { gerenciamento de } \\
\text { projetos. } \\
\text { Pirataria:Adoçao de } \\
\text { metodologia de controles } \\
\text { e bloqueio. }\end{array}$ \\
\hline 党 & $\begin{array}{l}\text { Publicadores: Requisitos } \\
\text { de qualidade, preço/prazo } \\
\text { criatividade/inovação } \\
\text { (referência } \\
\text { internacional).- } \\
\text { Interferência direta na } \\
\text { execução. Propriedade } \\
\text { intelectual sobre os } \\
\text { produtos (aquisição dos } \\
\text { direitos). } \\
\text { Usuário final: teste de } \\
\text { conceito }\end{array}$ & $\begin{array}{c}\text { Usuários finais: } \\
\text { exigência por maior } \\
\text { interface possível } \\
\text { Clientes corporativos } \\
\text { (de telefonia } \\
\text { móvel):interferências no } \\
\text { processo criativo e na } \\
\text { inovação: foco no } \\
\text { negócio (telefonia) e } \\
\text { pouco relacionado a } \\
\text { performance criativa }\end{array}$ & $\begin{array}{l}\text { Clientes corporativos: } \\
\text { exigencia de níveis de } \\
\text { qualidade, criatividade, } \\
\text { inovação preço e prazo. } \\
\text { Interferência direta na } \\
\text { execução. } \\
\text { Usuario final: teste de } \\
\text { conceito }\end{array}$ & $\begin{array}{l}\text { Publicadores e Clientes } \\
\text { corporativos: Requisitos } \\
\text { de qualidade, preço/prazo } \\
\text { criatividade/inovação } \\
\text { (referência internacional). } \\
\text { Interferência direta na } \\
\text { execução Usuário } \\
\text { final:teste de conceito } \\
\text { (focus groups). }\end{array}$ \\
\hline 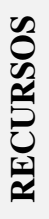 & $\begin{array}{l}\text { Ativo estratégico: } \\
\text { pessoas criativas } \\
\text { (proatividade e } \\
\text { autonomia) e contr. de } \\
\text { processos }\end{array}$ & $\begin{array}{c}\text { Ativo estratégico: } \\
\text { tecnologia própria } \\
\text { desenvolvida (rapidez de } \\
\text { resposta ao mercado). }\end{array}$ & $\begin{array}{l}\text { Ativo estratégico: } \\
\text { controle de processos. }\end{array}$ & $\begin{array}{l}\text { Ativo estratégico: } \\
\text { controle de processos. }\end{array}$ \\
\hline
\end{tabular}

Nota: Material empírico coletado e adaptado de Sashittal, H. C., \& Jassawalla, A. R. (2001). 
No conceito do composto de marketing, o produto é a variável de grande impacto sobre o processo de implementação e é influenciado diretamente pelos clientes quanto ao grau de customização dos projetos, ou seja, quanto à complexidade técnica e criativa, design, enredo, linguagem lúdica, idioma, tempo de produção e desempenho requerido para o jogo, conforme EA, EG e ED. Já o tipo de mídia ou plataforma onde serão rodados influencia na distribuição e também nas estratégias de comunicação/promoção, fato constatado em EA, EB, EG e ED. No que tange ao design organizacional, a interdisciplinaridade dos profissionais e o monitoramento dos processos são forças que incidem sobre a implementação. Pessoas, de diversas áreas relativamente integradas em equipes de trabalho, em torno de processos complexos correspondem a uma variável chave para execução das estratégias, fator que se apresentou como evidente nos quatros casos. O agrupamento multidisciplinar é uma característica do setor e o desafio da gestão é permitir a descentralização das decisões, favorecer a autonomia do grupo no processo criativo (EA) e estimular a tomada de decisões nas demandas de escopo (EB) e nas emergentes demandas dos clientes (EG, ED). “Cada grupo é autosuficiente e independente e a gente tem isso como estratégia." (g2EA). Embora a mão de obra necessária ao desenvolvimento dos jogos tenha esse caráter multidisciplinar, foram evidentes as considerações a respeito da necessidade de formá-la internamente e de promover treinamentos de forma a desenvolver competências. A Tabela 2 - Influências do nível operacional sobre as decisões estratégicas - traz variáveis que se destacaram na investigação. 
Tabela 2 - Influências do Nível Operacional sobre as Decisões Estratégicas

\begin{tabular}{|c|c|c|c|c|}
\hline \multicolumn{5}{|c|}{ ANTECEDENTES CONTEXTUAIS INFLUENTES NAS DECISÕES ESTRATÉGICAS } \\
\hline & Estúdio Alpha (EA) & Estúdio Beta (EB) & Estúdio Gamma (EG) & Estúdio Delta (ED) \\
\hline $\begin{array}{l}0 \\
\frac{0}{b} \\
\hat{0} \\
0 \\
\frac{\alpha}{2}\end{array}$ & $\begin{array}{l}\text { Projetos sob demanda } \\
\text { (entretenimento e } \\
\text { publicidade) para qualquer } \\
\text { plataforma ou gênero; alta } \\
\text { complexidade técnica e } \\
\text { criativa; idioma inglês ou } \\
\text { outro solicitado pelo } \\
\text { publicador }\end{array}$ & $\begin{array}{l}\text { Projeto de entretenimento; } \\
\text { controle total sobre o } \\
\text { produto desenvolvido e } \\
\text { sua plataforma; idioma: } \\
\text { inglês.Projetos sob } \\
\text { demanda (entretenimento } \\
\text { para telefonia móvel): } \\
\text { mais produtividade/menos } \\
\text { criatividade }\end{array}$ & $\begin{array}{c}\text { Projetos sob demanda } \\
\text { (treinamento/publicidade); } \\
\text { alta complexidade técnica } \\
\text { e criativa; adequação de } \\
\text { escopo/propósito do } \\
\text { cliente idioma: } \\
\text { português/inglês }\end{array}$ & $\begin{array}{c}\text { Projetos sob demanda } \\
\text { (entretenimento, } \\
\text { treinamento/publicidade); } \\
\text { complexidade e } \\
\text { sofisticação. } \\
\text { Projeto de entretenimento: } \\
\text { altos investimentos; } \\
\text { idioma: inglês/português }\end{array}$ \\
\hline 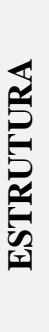 & $\begin{array}{l}\text { Orgânica, descentralizada, } \\
\text { baseada em projetos; } \\
\text { relações horizontais, } \\
\text { dinâmicas e colaborativas; } \\
\text { equipes integradas e auto- } \\
\text { coordenadas; estilo } \\
\text { participativo; regras e } \\
\text { procedimentos flexíveis. }\end{array}$ & $\begin{array}{l}\text { Orgânica, descentralizada, } \\
\text { relações horizontais, } \\
\text { dinâmicas entre sócios e } \\
\text { equipe;estilo participativo } \\
\text { dos desenvolvedores, mas } \\
\text { sob supervisão direta; } \\
\text { procedimentos flexíveis. }\end{array}$ & $\begin{array}{l}\text { Orgânica, descentralizada, } \\
\text { baseada em projetos; } \\
\text { relações horizontais, } \\
\text { dinâmicas e colaborativas; } \\
\text { equipes integradas e } \\
\text { coordenadas por gerente } \\
\text { de arte e de projeto; regras } \\
\text { e procedimentos flexíveis. }\end{array}$ & $\begin{array}{l}\text { Orgânica, baseada em } \\
\text { projetos; relações } \\
\text { horizontais, dinâmicas e } \\
\text { colaborativas; equipes } \\
\text { integradas e coordenadas } \\
\text { por líder de projeto; regras } \\
\text { e procedimentos flexíveis. }\end{array}$ \\
\hline 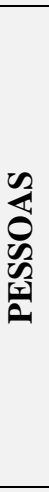 & $\begin{array}{l}\text { Requisitos: Profissional } \\
\text { multidisciplinar, criativo, } \\
\text { usuário de games. } \\
\text { Diferenciais valorizados } \\
\text { criatividade, proatividade, } \\
\text { autonomia. } \\
\text { Coordenador: visão } \\
\text { técnica do software, da } \\
\text { arte, criação e habilidade } \\
\text { para gestão de pessoas. }\end{array}$ & $\begin{array}{c}\text { Requisitos: Profissional } \\
\text { multidisciplinar } \\
\text { (inteligência artificial e } \\
\text { programação), criativo, } \\
\text { usuário de games. } \\
\text { Diferenciais valorizados: } \\
\text { envolvido com tecnologia } \\
\text { e respostas dinâmicas às } \\
\text { informações do ambiente. } \\
\text { Coordenador: liderança } \\
\text { para controle efetivo das } \\
\text { metas. }\end{array}$ & $\begin{array}{c}\text { Requisitos: Profissional } \\
\text { multidisciplinar, criativo, } \\
\text { usuário de games. } \\
\text { Diferenciais valorizados: } \\
\text { organização e controle, } \\
\text { proposição de soluções } \\
\text { inovadoras; criatividade, } \\
\text { proatividade, autonomia. } \\
\text { Coordenadores: habilidade } \\
\text { em arte e gerencia de } \\
\text { projetos. }\end{array}$ & $\begin{array}{l}\text { Requisitos: Profissional } \\
\text { multidisciplinar, criativo, } \\
\text { usuário de games. } \\
\text { Diferenciais valorizados: } \\
\text { proatividade, autonomia; } \\
\text { expertise, criatividade. } \\
\text { Coordenação: líder em arte } \\
\text { e tecnologia, habilidades } \\
\text { de gestão. }\end{array}$ \\
\hline 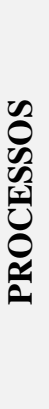 & $\begin{array}{c}\text { Foco: Controle } \\
\text { Controle de alterações e } \\
\text { interferências dos clientes; } \\
\text { adoção de metodologia } \\
\text { (SCRUM); controle do } \\
\text { cronograma (prazo). } \\
\text { Testes contínuos da } \\
\text { formulação à } \\
\text { implementação (para } \\
\text { validação). }\end{array}$ & $\begin{array}{c}\text { Foco: tecnologia } \\
\text { Processo adequado à } \\
\text { tecnologia desenvolvida } \\
\text { internamente. } \\
\text { Controle: por meio de } \\
\text { cronograma. }\end{array}$ & $\begin{array}{c}\text { Foco: Controle } \\
\text { Controle da documentação } \\
\text { (escopo); do cronograma } \\
\text { (prazo); das alterações } \\
\text { (mudanças); } \\
\text { Testes contínuos da } \\
\text { formulação à } \\
\text { implementação (para } \\
\text { validação). }\end{array}$ & $\begin{array}{l}\text { Foco: Controle } \\
\text { Controle de alterações } \\
\text { (interferências dos } \\
\text { clientes); controle do } \\
\text { cronograma (prazo). } \\
\text { Testes contínuos da } \\
\text { formulação à } \\
\text { implementação (para } \\
\text { validação). }\end{array}$ \\
\hline
\end{tabular}

Nota: Material empírico coletado e adaptado de Sashittal, H. C., \& Jassawalla, A. R. (2001).

Um destaque importante que se faz é quanto à variável processos ainda no âmbito da análise das forças influentes no nível operacional. Nos quatro casos há visão de mapeamento de processos (planejamento, cronograma e fluxo de trabalho) assim como utilização de ferramentas que apóiam e 
controlam as etapas de desenvolvimento dos jogos. Embora demonstre caráter flexível, o controle, também evidenciado nos quatro casos, é fator chave para efetividade do processo de implementação das estratégias. Interferências dos clientes atuam alterando principalmente aspectos relativos a escopo e cronograma, o que leva a refazer etapas e a ajustar o prazo de acordo com todos os entrevistados. O EA por exemplo, se utiliza da técnica de validação intermediária semanal: "Sempre às quintas-feiras entregamos uma 'build' para o cliente. Ele joga e dá o retorno sobre as avaliações feitas, apontando mudanças. Essas alterações entram novamente em planejamento" $(g 2 E A)$.

\subsection{ESCOLHAS GERENCIAIS}

Representando a combinação de escolhas e habilidades que integram empresas aos seus ambientes, as escolhas gerenciais são baseadas no relacionamento entre planejadores e implementadores e nas habilidades estratégicas para interpretar o mercado, integrar informações externas ao ambiente tarefa e no comprometimento da empresa com clientes (Sashittal e Jassawalla, 2001). A investigação nos estúdios revelou que a integração entre planejadores e implementadores é condição essencial para o sucesso dos projetos de jogos (EA, EB, EG, ED). Conforme enfatizado pelos estúdios, as equipes executoras, ao se envolverem frequentemente nas decisões de planejamento, contribuem com informações baseadas em sua experiência e na sua real capacidade de produção, possibilitando, inclusive, diminuição de riscos e de alguns custos operacionais relacionados às estratégias comerciais. Esse processo ocorre de forma sistemática e simultânea e como conseqüência há certa relação produtiva originada no comprometimento e no interrelacionamento. Quanto às habilidades de interpretar demandas externas, identificou-se que as decisões se baseiam na estratégia de orientação para o mercado que, conforme Day (1994), dentre outros fatores, se baseia na capacidade elevada para atrair e manter clientes importantes, na adoção de processos inovadores, no monitoramento da concorrência e na aproximação com os clientes tanto quanto possível, processo que deve envolver toda a organização. Corroborando com essa perspectiva, normalmente os estúdios trabalham com projetos sob encomenda de acordo com critérios e necessidades definidos pelos clientes (publicadores e corporativos) e, quando necessário, desenvolvem tecnologias próprias internamente de forma ágil, minimizando custos e facilitando os processos, o que é apontado como diferencial competitivo nesse ambiente.

De forma complementar, a habilidade integrativa foi observada em todos os casos no desenvolvimento de produtos de acordo com as tendências e na utilização de técnicas de controle dos processos, para eficiência, redução de riscos e para que os projetos de jogos possam ser 
Processos de Implementação de Estratégias de Marketing na Indústria Criativa de Jogos Eletrônicos adaptados aos ajustes propostos pelos clientes. E a habilidade para se comprometer com mercados e clientes, por sua vez, manifestou-se no estreito relacionamento mantido com usuários, inclusive para teste de conceito, com clientes e fornecedores. Além disso, os quatro casos manifestaram flexibilidade e realinhamento dos processos em razão de adequações demandadas, nas soluções apresentadas de maneira ágil e nos controles e validações intermediárias previstas nos processos produtivos (EA, EB, EG, ED).

A responsividade dos estúdios foi observada nas improvisações e adaptações, principalmente em resposta às demandas dos clientes. Porém, vinculadas de maneira mais acentuada às forças do nível operacional, tais improvisações ou adaptações não demonstraram comprometer as deliberadas escolhas gerenciais sobre o negócio e sobre os processos de maneira geral. A utilização de processos flexíveis e de técnicas de controle baseadas em metodologias de gerenciamento de projetos foi sinalizada como forma de minimizar a ocorrência de improvisações. "É possível ter uma visão muito clara sobre o que é possível construir e o uso do 'Scrum' permite flexibilidade para que seja feita alguma modificação dentro do estipulado no processo" (g2EA). Registra-se que o Scrum é ferramenta da área de produção de softwares adotada por EA e por ED e permite manter rápida e contínua inspeção nas etapas de desenvolvimento.

\subsection{EFETIVIDADE DAS ESTRATÉGIAS: INDICADORES E RESULTADOS}

A efetividade no processo de implementação, conforme proposto no Modelo de Sashittal e Jassawalla (2001) foi avaliada pelo desempenho e alcance dos objetivos com relação a mercados atendidos (internos/externos), clientes conquistados e produtos desenvolvidos (títulos publicados, histórico dos jogos desenvolvidos, tipo de projeto ou de mídia utilizada). Paralelamente à análise desses resultados, detectou-se que há um processo sistematizado de validação com o cliente para aceitação das fases do jogo já desenvolvidas, o que demonstra efetividade sobre o relacionamento e sobre a execução, aspecto observado nos quatro casos.

Com relação aos resultados obtidos pela equipe em termos de satisfação, o material empírico coletado não registrou nenhum processo formal nos estúdios. Ainda assim, foi possível avaliar que a fusão de competências, de habilidades técnicas e a capacidade de quebrar paradigmas nos processos de gestão, quando suportados pela flexibilidade administrativa e pela ampla participação de todos na tomada de decisões, aspectos característicos de uma estrutura orgânica (conforme perspectiva de Mintzberg, 2006c, quando aborda o papel das estruturas organizacionais em relação à estratégia), apresentaram-se como promotores de clima organizacional positivo no ambiente dos estúdios, 
favorecendo a motivação para a execução das tarefas e a liberação das habilidades criativas, conforme apontado por Amabile (1997) em sua teoria. "O jogo é artístico, é técnico, é criação...E um trabalho desse segmento é saber unir a pessoa que vem da área artística, do design, com o programador, com a parte técnica"(gB). "Nós trabalhamos sempre com pessoas de alto nível de instrução, mas a motivação delas não é só financeira. Tem orgulho de trabalhar na empresa!" (g2EA).

\subsection{INFLUÊNCIA DA CRIATIVIDADE E DA INOVAÇÃO NO PROCESSO DE IMPLEMENTAÇÃO}

A habilidade criativa necessária para desenvolvimento dos jogos e o foco dado à inovação são premissas para manter negócios nesse mercado, de acordo com Tschang e Vang (2008) e DyerWitherford e Sharman (2005). Esse aspecto foi enfatizado pelos gestores dos quatro estúdios.

A capacidade das equipes de criação em agir com base nas tendências tecnológicas, culturais e artísticas relacionadas ao setor de entretenimento e à tecnologia das novas mídias, percebida nos casos estudados, se alia, no nível funcional, à capacidade técnica (mão de obra multidisciplinar e qualificada presente nos estúdios) e à competência criativa no desenvolvimento de produtos. " $E$ importante trabalharmos com pessoas que sejam sempre, não só formadores de opinião, mas que estejam na vanguarda das tendências. Esse é o tipo de pessoas que trabalham com a gente. Esse é o tipo de criatividade que a gente precisa” (g2EA).

Considerando que o comportamento criativo instaurado nos estúdios é um ativo estratégico, esses fatores podem ser tomados como um repositório de vantagens competitivas para a indústria e canal de entrega de valor, conforme perspectiva de Cohendet e Simon (2007) e de Piercy (2005). Ainda assim, embora a motivação para a execução de atividades de forma criativa e a própria criatividade possam ser consideradas ativos intangíveis e elementos fundamentais para o sucesso no desenvolvimento dos jogos, há pouca interferência ou quase nenhum controle sobre ambas por parte dos administradores dos estúdios. Como comenta um dos gestores do Estúdio Alpha: “ $A$ criatividade é importante, mas não é algo que eu possa impor. É inspiração... e vem em momentos diferentes, em situações diferentes" (g1EA).

Essa consideração faz com que as empresas se utilizem de fatores extrínsecos, tais como ambiente propício, fluidez na comunicação interna e outras motivações como ambiência física (infraestrutura e equipamentos de última geração) e a comunicação visual como fatores estimulantes para a mobilização do potencial criativo, fato observado nos quatro estúdios. 
Processos de Implementação de Estratégias de Marketing na Indústria Criativa de Jogos Eletrônicos

A orientação à inovação foi avaliada na percepção da tecnologia de processo adotada, no conhecimento mobilizado e nas habilidades no desenvolvimento dos jogos, com emprego de soluções inovadoras. As habilidades dos gestores em interpretar tendências, em integrar informações externas decisivas e em estimular o comprometimento e a responsividade da equipe para com clientes e mercado respaldaram a análise da motivação organizacional para inovar. Nesse sentido foi possível perceber consequiências diretas da orientação à inovação sobre o composto de marketing, com relação a produtos e serviços: agilidade nos lançamentos (ED), o uso de tecnologias existentes incrementadas com diferenciais inovadores (EA, EG, ED), preços praticados, com melhor custo benefício para os clientes, (EA, ED), eficiência no processo de distribuição, considerando escolha de plataformas ou mídias adequadas ao público alvo (EB) e uso intensivo do processo de comunicação, com identificação de canais virtuais alternativos para aproximação com público alvo, a exemplo do apoio de redes sociais (EA, EB, EG, ED). Essa análise corrobora com as perspectivas de Dyer-Witherford e Sharman (2005), quando enfocam o emprego de recursos inovadores no processo produtivo dos jogos sob condições rígidas de eficiência, e com a perspectiva de Amabile (1997), em relação à influência que esses recursos exercem sobre a criatividade individual e grupal, endossando a extensão dessas sobre a própria inovação no processo de implementação de estratégias de marketing nos estúdios. "Essa capacidade inovadora que permeia todas as partes da empresa é uma das principais características dela hoje e que não só influencia no gerenciamento dos processos, mas também nos clientes que estamos conseguindo conquistar" (g3EG).

Finalizando a apresentação da análise dos dados, na seção seguinte é apresentada avaliação dos resultados alcançados, com destaque para os fatores organizacionais e humanos identificados na investigação, considerados suportes para os processos de implementação.

\section{DISCUSSÃO DOS RESULTADOS}

No conjunto das forças que mais exercem influência sobre as decisões de implementação nesses ambientes, à luz das proposições de Sashittal e Jassawalla (2001), destacam-se as variáveis tecnologia e clientes. A tecnologia, com suas ondas de mudança e inovação, mobilizam toda a cadeia produtiva, e os clientes, principalmente os publicadores, detêm conhecimento das tendências e das inovações e influenciam diretamente no desenvolvimento dos jogos. De forma complementar, no âmbito das escolhas estratégicas identificou-se que os objetivos de marketing, o emprego dos recursos (humanos e tecnológicos) e os componentes do design organizacional (principalmente 
pessoas, processos e estrutura) são variáveis que se destacam na execução das estratégias. Observou-se que os estúdios correspondem a estruturas organizacionais inovadoras, fluidas e, de acordo com Mintzberg (2006c), estruturas com esta configuração trabalham normalmente com estratégias emergentes, e há dependência e integração entre planejamento e execução para responder criativamente aos desafios de seu ambiente. As habilidades criativas, o emprego de inovadoras técnicas de controles, assim como certos padrões de gestão puderam ser analisados de forma associada aos resultados alcançados, apresentando indícios de que uma visão que integra processo, orientação para o mercado e entrega de valor, embasada na expertise criativa dos estúdios, são requisitos para a efetividade do processo de implementação de estratégias no desenvolvimento de jogos eletrônicos. Consolidando essa idéia, alguns elementos se destacaram como essenciais para a execução de estratégias nessa indústria criativa e durante a análise dos casos foram agrupados em fatores organizacionais e humanos conforme proposição de Sashittal e Jassawalla (2001).

Ao se analisarem os fatores organizacionais à luz da teoria, algumas considerações se fazem pertinentes. Com relação à orientação para o mercado, a implementação de estratégias se baliza na tendência delineada pelos competidores da indústria como um todo, principalmente nas diretrizes dos publicadores. A habilidade requerida para se comprometerem com mercados e clientes (Sashittal e Jassawala, 2001) é evidenciada no propósito dos estúdios de manterem contínuo aprendizado sobre o movimento dos mercados de tecnologia e entretenimento, verificando tendências que possam ser capturadas como oportunidades. Em relação à execução, a complexidade, a sofisticação técnica, o tempo de desenvolvimento expõem os projetos a vulnerabilidades (prazos de entrega, alterações e revisões de escopo) incidindo em riscos e custos. Além disso, pelo fato de se manter foco no cliente, gera-se uma estratégia participativa do próprio cliente e, portanto, o uso de uma tecnologia de processos, com ferramentas de controle, passa a ser um resistente efeito controlador das interferências de emergentes decisões, ou de improvisações apontadas por Sashittal e Jassawalla (2001) como forças influentes sobre escolhas gerenciais.

Registra-se ainda que as formas organizacionais inovadoras de gerenciar as operações, de manter o equilíbrio exigido entre criatividade e racionalização, de coordenar equipes por meio de fluxo dinâmico de comunicação e execução de atividades operacionais, com esforço concentrado em processos e controles, apresentam-se vinculadas de forma estreita à efetividade da implementação de estratégias nessa indústria criativa. Para melhor visualização desse tema, apresenta-se a Tabela 4 - Fatores organizacionais. E na sequência, são apresentados os fatores humanos, sintetizados da mesma forma. 
Processos de Implementação de Estratégias de Marketing na Indústria Criativa de Jogos Eletrônicos

Tabela 4 - Fatores Organizacionais Evidenciados no Processo de Implementação de Estratégias

\section{FATORES ORGANIZACIONAIS}

\section{ESTRUTURA ORGÂNICA E FORMAÇÃO DE GRUPOS DE TRABALHO EM TORNO DE PROJETOS}

Teoria - circunstâncias favoráveis

Análise da configuração da estrutura organizacional (linhas de autoridade, divisão de trabalho, subordinação)

- Estrutura orgânica: fluida, especialização do trabalho, especialização horizontalizada, especialistas em pequenas equipes de projetos; pouca importância aos sistemas regulados; pouca formalização; fluência nos processos de informação e decisão (Mintzberg, 2006c).

- Estruturas orgânicas incentivam as comunicações horizontais e verticais e atividades e práticas flexíveis (Olson, Slater e Hult, 2005)

\section{Evidências}

Estrutura observada como orgânica; relações dinâmicas horizontais e colaborativas, comunicação fluida.

- Constituição de equipes de projetos (descentralização/autonomia): fusão de especialistas de diferentes áreas trabalhando de forma homogênea (designers, programadores, profissionais de computação gráfica, sonoplastas).

\section{COMPETÊNCIA NA ORIENTAÇÃO PARA O MERCADO}

Teoria - circunstâncias favoráveis

Análise das opções estratégicas da empresa em relação ao mercado.

Empresas orientadas para o mercado: capacidade elevada para atrair/manter clientes importantes; adoção de processos inovadores, aproximação com clientes; disciplina para fazer opções estratégicas saudáveis envolvendo toda a organização (Day, 1994)

Ativo estratégico crítico do negócio: concentração no cliente (Piercy, 2005)

- Oferta de produtos de acordo com as necessidades dos clientes: opção estratégica com impacto sobre alocação de recursos tecnológicos, humanos, financeiros e de suporte (Day, 1994)

\section{Evidências}

- Produtos sob medida: foco no cliente.

- Aproximação com o mercado influente: publicadores e distribuidores.

- Adoção de padrões internacionais de gerenciamento de projetos.

Inglês como padrão.

- Manutenção de contato com clientes por todos da equipe: estratégia participativa e relacionamento colaborativo.

\section{TECNOLOGIA DE PROCESSOS}

Teoria - circunstâncias favoráveis

Análise de como os processos são executados e transformados em ativos estratégicos

- Eficácia operacional: componente imprescindível da gestão e essencial para a estratégia (Porter, 1999)

Práticas de gestão inovadoras: diferenciação nos processos, emprego de determinados recursos necessários para o alcance da inovação e expertise técnica e criativa (Amabile, 1997)

\section{Evidências}

- Práticas de gestão inovadoras: uso de metodologia de gestão de projetos (PMBOK), métodos de controles e acompanhamento (Grafico de Gant),

- Execução disciplinada, sistematizada e contínua de processos; monitoramento para blindar e minimizar riscos (metodologia ágil/Scrum).

- Emprego de recursos humanos (expertise), tecnológicos e financeiros para suporte a inovação.

Nota: Estruturado com base no material empírico coletado e analisado na investigação 
De forma complementar a esses fatores acrescenta-se os fatores humanos, nos quais está evidenciada a força da criatividade dos envolvidos no processo de implementação de estratégias de marketing nesses ambientes. Ao considerar os argumentos de Sashittal e Jassawala (2001) sobre a gestão da criatividade como resposta às forças do mercado, parece que suas afirmações são consistentes com a forma criativa dos estúdios em bloquear, ainda que de maneira emergente, possíveis impactos negativos dos movimentos do mercado. Conectando tais idéias às proposições de Amabile (1997), embora a habilidade criativa e a propensão à inovação não pareçam ser determinantes exclusivas do sucesso dos negócios de desenvolvimento de jogos, é possível perceber que as motivações para o exercício da criatividade, tanto pessoais como no ambiente organizacional, assim como a inovação impactam de maneira cíclica as habilidades estratégicas e a manutenção dos diferenciais competitivos, humanos e organizacionais, afetando positivamente o processo de implementação de estratégias de marketing. A seguir, a Tabela 5 - Fatores humanos evidenciados no processo de implementação de estratégias, expõe de forma sintética o assunto apontando a teoria e os elementos destacados no estudo. 
Processos de Implementação de Estratégias de Marketing na Indústria Criativa de Jogos Eletrônicos

Tabela 5 - Fatores Humanos Evidenciados no Processo de Implementação de Estratégias

\begin{tabular}{|c|c|}
\hline \multicolumn{2}{|l|}{ FATORES HUMANOS } \\
\hline \multicolumn{2}{|c|}{ 1. EQUIPES MULTIDISCIPLINARES, CRIATIVAS, AUTOMOTIVADAS } \\
\hline $\begin{array}{l}\text { Teoria - circunstâncias favoráveis } \\
\text { Análise da formação de grupos de trabalho/ agrupamentos } \\
\text { orgânicos } \\
\text { Organização de equipes de trabalho em organizações } \\
\text { inovadoras: sistema de constelações de trabalho para lidar com } \\
\text { os diferentes aspectos de seu ambiente (Mintzberg,2006c) } \\
\text { Implantaçao de estruturas de geometria variável: facilita } \\
\text { sinergia e intercâmbio de competências e evita a } \\
\text { compartimentalização do saber a uma determinada hierarquia } \\
\text { de grupo (Toaldo, Jotz e Luce, 2008) } \\
\text { Características e habilidades comportamentais: necessidade de } \\
\text { motivação e comprometimento, atitudes e comportamento, } \\
\text { como essenciais para entrega de valor (Piercy, 1998, 2005) }\end{array}$ & $\begin{array}{l}\text { Evidências } \\
\text {. Formação de constelações de trabalho, } \\
\text { com diferentes expertises, integrando } \\
\text { planejadores e implementadores / } \\
\text { novatos e experientes na interpretação } \\
\text { de tendências ( game designers, } \\
\text { programadores, artistas) } \\
\text {. Intercâmbio de competências: um } \\
\text { mesmo game-designer pode fazer parte } \\
\text { de uma equipe e na outra ser } \\
\text { considerado o supervisor. } \\
\text { Envolvimento emocional: motivação por } \\
\text { trabalhar com processos criativos, arte e } \\
\text { histórias (enredo). }\end{array}$ \\
\hline \multicolumn{2}{|c|}{ 2. COMPETÊNCIA GERENCIAL } \\
\hline $\begin{array}{l}\text { Teoria - circunstâncias favoráveis } \\
\text { Análise de padrões de gestão e habilidades gerenciais } \\
\text { Habilidade interpetativa, integrativa e habilidade de se } \\
\text { comprometer com mercados e clientes (Sashittal e Jassawalla, } \\
2001 \\
\text { Habilidade de se comprometer com a estratégia (Noble e } \\
\text { Mokwa, 1999) } \\
\text { Gerentes devem ser mestres em relações humanas, capazes de } \\
\text { usar a persuasão, a negociação, a coalizão, a reputação e a } \\
\text { camaradagem para reunir seus especialistas em equipes } \\
\text { autônomas para funcionarem de forma descentralizada e } \\
\text { tranquilamente (Mintzberg, 2006b) } \\
\text { força de trabalho técnica e criativa, formada por especialistas, } \\
\text { de quem normalmente é exigido equilíbrio entre criatividade e } \\
\text { racionalização (Cohendet \& Simon, 2007; Perucia, Balestrin, } \\
\text { \& Verschoore, 2009). }\end{array}$ & $\begin{array}{l}\text { Evidências } \\
\text { Gestores: habilidades de liderança e } \\
\text { habilidades visionárias; } \\
\text { - Flexibilidade para atender ao mercado } \\
\text { externo com oferta de criatividade e } \\
\text { menores custos } \\
\text { - Equilíbrio entre confiança, flexibilidade } \\
\text { e descentralização na gestão de } \\
\text { múltiplas expertises } \\
\text { - Atitude administrativa que integra } \\
\text { restrições internas e de mercado, custos, } \\
\text { prazo, tecnologia. } \\
\text { - Estilo de administração participativo: } \\
\text { estímulo à autonomia das pessoas e } \\
\text { equipes e incorporação da diversidade } \\
\text { como um valor essencial. }\end{array}$ \\
\hline \multicolumn{2}{|c|}{ 3. ESTÍMULO ÀS HABILIDADES CRIATIVAS EM RESPOSTA AS FORÇAS DO MERCADO } \\
\hline $\begin{array}{l}\text { Teoria - circunstâncias favoráveis } \\
\text { Análise das habilidades criativas no contexto da } \\
\text { implementação de estratégias } \\
\text { Criatividade e inovação emergem como elementos } \\
\text { complementares (Amabile, 1997), } \\
\text { Gestão da criatividade como resposta às forças do mercado: } \\
\text { reflexo nas decisões sobre improvisações e adaptações, } \\
\text { construção e reforço dos relacionamentos com clientes e } \\
\text { manutenção de seu posicionamento no mercado.( Sashittal e } \\
\text { Jassawala, 2001), }\end{array}$ & $\begin{array}{l}\text { Evidências } \\
\text { Integração da multidisciplinaridade } \\
\text { criativa da equipe à tecnologia de } \\
\text { processos e à forma como as atividades } \\
\text { operacionais são administradas } \\
\text { - Existência de uma gestão da criatividade } \\
\text { efetiva em resposta às forças do } \\
\text { mercado } \\
\text { - Elite técnica e criativa: pessoas no limiar } \\
\text { das tendências e que conhecem } \\
\text { tecnologia e inovação } \\
\text { - Produtos premiados como valorização } \\
\text { da criatividade da equipe }\end{array}$ \\
\hline
\end{tabular}

Nota: Estruturado com base no material empírico coletado e analisado na investigação 
Concluindo a discussão dos resultados, salienta-se que, embora os elementos que compõem os fatores organizacionais e humanos possam ser encontrados de forma isolada em estudos já realizados, nesta análise esses fatores foram apresentados como inter-relacionados e resultantes das características funcionais específicas do ambiente criativo estudado e da reflexão sobre aspectos relacionados à execução de estratégias de marketing que se configuraram como tangíveis e reais no decurso da investigação.

\section{CONSIDERAÇÕES FINAIS}

Ainda que a análise feita no referencial teórico tenha permitido perceber que a noção conjunta e integrada de alguns conhecidos elementos estratégicos seja bastante útil na compreensão dos processos de implementação de estratégias de marketing em pequenas empresas, futuras investigações, que contemplem processos de implementação em ambientes que utilizam criatividade e inovação como valor de mercado e ferramenta competitiva, poderão incluir variáveis percebidas como mais influentes nessa análise, conforme exposto na discussão dos resultados. À luz da contribuição que esses resultados intencionam aportar ao conhecimento sobre a execução de estratégias de marketing em ambientes criativos, sugere-se que sejam considerados também como elementos favoráveis ao processo de implementação: a tecnologia de processo, os controles e a habilidade dos envolvidos.

Tecnologia de processo: tanto na produção, no desenvolvimento ou na administração, processos podem ser criativos e inovadores e, se conduzidos de maneira adequada, servem como ativo estratégico e manutenção de vantagens competitivas. Os resultados do estudo contribuem para com a teoria, ao apontarem que dentro das práticas de gestão inovadoras e de estímulo às habilidades criativas, as atividades que promovem a eficácia operacional, se executadas de forma disciplinada, sistematizada e contínua, tendem a evoluir e podem convergir em padrões de gestão recorrentes para contínua entrega de valor.

Controles: processos eficientes requerem monitoramento e controles. Nesse sentido, e como contribuição dos resultados ao Modelo de Sashittal e Jassawalla (2001), sugere-se que às categorias de análise apontadas pelos autores sejam incrementadas variáveis de controle, com a função de auxiliarem no monitoramento qualitativo da implementação. Controles e monitoramento efetivo podem fortalecer os mecanismos estruturais e sistêmicos da organização, auxiliando as mudanças, quando necessárias, e, paralelamente, podem bloquear improvisações que interferirão nos processos de implementação e nas vantagens competitivas. 
Processos de Implementação de Estratégias de Marketing na Indústria Criativa de Jogos Eletrônicos

Habilidades e competências dos envolvidos: a identificação de precisas competências estratégicas do corpo gerencial é condição essencial para que o processo de implementação tenha êxito. Embora Sashittal e Jassawalla (2001) tenham enfatizado a importância das habilidades estratégicas no contexto das escolhas gerenciais em seu modelo, sugere-se que a essa categoria sejam incluídas também as competências gerenciais. As habilidades estratégicas se relacionam à interpretação, à integração e ao comprometimento da empresa com o mercado. No entanto, a identificação de precisas competências estratégicas do corpo gerencial é condição essencial para que o processo de implementação tenha resultado (Noble \& Mokwa, 1999). Como contribuição dos resultados do estudo, sugere-se agregar ao Modelo de Sashittal e Jassawalla (2001), na categoria 'Escolhas Gerenciais', alguns conceitos comportamentais, integrando a habilidade geral da organização com a habilidade específica do corpo gerencial, no que concerne às competências pessoais que servem de apoio à efetividade da estratégia.

De maneira conclusiva, registra-se que o artigo procurou apresentar apenas uma visão geral da análise feita na investigação, considerando fatores influentes no processo de implementação de estratégias de marketing nessa indústria criativa em particular. Em oportunidades futuras, limitações que tenham sido evidenciadas poderão ser minimizadas com novas investigações, seja em estudos no ambiente de desenvolvimento de jogos ou em outros segmentos das indústrias criativas, para as quais se sugerem algumas temáticas: estudos comparativos sobre estratégia e posicionamento de mercado dos estúdios brasileiros; estudos longitudinais na perspectiva de sistematização de informações relacionadas ao desempenho dos jogos produzidos por estúdios brasileiros para o mercado nacional e global; e ainda, estudos quantitativos, com escalas que meçam aspectos comportamentais e motivacionais de envolvidos na execução de estratégias no âmbito de empresas criativas. 


\section{REFERÊNCIAS}

Aaker, D. (2001). Administração estratégica de mercado. Porto Alegre: Bookman.

Amabile, T. M. (1997). Motivating creativity in organizations: on doing what you Love and loving what you do. California Management Review, 40(1), 39-58.

Andrews, K. (2006). O conceito de estratégia corporativa. In H. Mintzberg, J. Lampel, J. B. Quinn, \& S. Ghoshal (Eds.), O processo da estratégia. Conceitos, contextos e casos selecionados (4a ed., pp. 78-84). Porto Alegre: Bookman.

Ansoff, I. (1977). Estratégia empresarial. São Paulo: McGraw Hill.

Ansoff, I. (1990). A nova estratégia empresarial. São Paulo: Atlas.

Bardin, L. (2002). Análise de conteúdo. Lisboa: Edições 70.

Bendassolli, P. F., Wood, T., Jr., Kirschbaum, C., \& Cunha, M. P. (2009). Compreendendo as indústrias criativas. In T. Wood, Jr., P. F. Bendassolli, C. Kirschbaum, \& M. P. Cunha (Coords.), Indústrias criativas no Brasil (pp. 24-35). São Paulo: Atlas.

Bonoma, T. V., \& Crittenden, V. L. (1988). Managing marketing implementation. Sloan Management Review, 29(2), 7-14.

Céspedes, E., \& Piercy, N. (1996). Implementing marketing strategy. Journal of Marketing Management, 12(1), 135-160.

Cohendet, P., \& Simon, L. (2007). Playing across the playground: paradoxes of knowledge creation in the video-game industry firm. Journal of Organizational Behavior, 28(5), 587-

605. doi: $10.1002 /$ job.460

Conferência das Nações Unidas para o Comércio e Desenvolvimento -Unctad (2008). Creative economy report 2008. Geneva: Autor. Recuperado em 15 outubro, 2008, de http://www.unctad.org/creative-economy

Day, G. S. (1992). Marketing's contribution to the strategy dialogue. Journal of the Academy of Marketing Science, 20(4), 323-329.

Day, G. S. (1994). The capabilities of market-driven organizations. Journal of Marketing, 58(4), 3753. 
Processos de Implementação de Estratégias de Marketing na Indústria Criativa de Jogos Eletrônicos

Department for Culture, Media and Sport. ( 2001). Creative industries mapping document. London: HMSO. Recuperado em 17 fevereiro, 2009, de http://www.culture.gov.uk/NR/rdonlyres/338EFCBC-F706-4191-A1A4CCB7EFF7EDAE/0/foreword.pdf

Dyer-Witherford, N., \& Sharman, Z. (2005). The political economy of Canada's video and computer game industry. Canadian Journal of Communication, 30(2), 187-210.

Flew, T. (2002). Beyond ad hocery: defining creative industries. Proceedings of the Conference on Cultural Policy Research, Wellington, New Zealand, 2. Recuperado em 15 março, 2009, de http://www.library.auckland.ac.nz/subjects/bus/execprog/docs/creative_industries.pdf

Gil, A. C. (2009). Como elaborar projetos de pesquisa (4a ed.). São Paulo: Editora Atlas.

Hrebiniak, L. G. (1990, April). Implementing strategy. Chief Executive, 57, 74-77.

Hrebiniak, L. G. (2006). Fazendo a estratégia funcionar: o caminho para uma execução bemsucedida. Porto Alegre: Bookman.

Jeffcutt, P. (2009). O ecossistema das indústrias criativas. In T. Wood, Jr., P. F. Bendassolli,C. Kirschbaum, \& M. P. Cunha (Coords.), Indústrias criativas no Brasil (pp. 36-56). São Paulo: Atlas.

Lawrence, T. B., \& Phillips, N. (2009). Compreendendo as indústrias culturais. In T. Wood, Jr., P. F. Bendassolli, C. Kirschbaum, \& M. P. Cunha (Coords.), Indústrias criativas no Brasil (pp. 323). São Paulo: Atlas.

Martins, G. A. (2008). Estudo de um caso: uma estratégia de pesquisa (2a ed.). São Paulo: Atlas.

Menon, A., Bharadway, S. G., Adidam, P. T., \& Edison, S. W. (1999). Antecedents and consequences of marketing strategy making. A model and a test. Journal of Marketing,63(2), 18-40. doi: 10.2307/1251943

Miles, I., \& Green, L. (2008). Hidden innovation in the creative industries. (Relatório de Pesquisa), London, National Endowment for Science, Technology and the Arts.

Miles, R. E., Snow, C. C., Mathews, J. A., Miles, G., \& Coleman, H. J., Jr. (2006). Antecipando a forma celular. In H. Mintzberg, J. Lampel, J. B. Quinn, \& S. Ghoshal (Eds.), O processo da estratégia. Conceitos, contextos e casos selecionados (4a ed., pp. 351-353). Porto Alegre: Bookman.

Mintzberg, H. (2004). Ascensão e queda do planejamento estratégico. Porto Alegre: Bookman. 
Mintzberg, H. (2006a). Cinco Ps para estratégia. In H. Mintzberg, J. Lampel, J. B. Quinn, \& S. Ghoshal (Eds.), O processo da estratégia. Conceitos, contextos e casos selecionados (Cap. 1.1, pp. 24-29). Porto Alegre: Bookman.

Mintzberg, H. (2006b). Moldando a estratégia. In H. Mintzberg, J. Lampel, J. B. Quinn, \& S. Ghoshal (Eds.), O processo da estratégia. Conceitos, contextos e casos selecionados (Cap. 5.1, pp. 130-136). Porto Alegre: Bookman.

Mintzberg, H. (2006c). Criando organizações eficazes: estruturas em cinco configurações (2a ed.) São Paulo: Atlas.

Mintzberg, H., Ahlstrand, B., \& Lampel, J. (2000). Safári de estratégia: um roteiro pela selva do planejamento estratégico. Porto Alegre: Bookman.

Mintzberg, H., Lampel, J., Quinn, J. B., Ghoshal, S. (2006). O processo da estratégia. Conceitos, contextos e casos selecionados. Porto Alegre: Bookman.

MSI - Marketing Science Institute. Research Priorities: 2008-2010. Guide to MSI Reseach Programs and Procedures. 2008. Recuperado em 15 maio, 2008 de http://www.msi.org/pdf/MSI_RP08-10.pdf.

Noble, C. H., \& Mokwa, M. P. (1999). Implementing marketing strategies: developing and testing a managerial theory. Journal of Marketing, 63(4), 57-73.

Olson, E. M., Slater, S. F., \& Hult, T. M. (2005). The importance of structure and process to strategy implementation. Business Horizons, 48(1), 47-54.

Perucia, A.S, Balestrin, A, \& Verschoore, J. R. (2009). Software: Estratégias colaborativas na indústria de jogos eletrônicos. In T. Wood, Jr., P. F. Bendassolli, C. Kirschbaum, \& M. P. Cunha (Coords.), Indústrias criativas no Brasil (pp. 138-152). São Paulo: Atlas.

Piercy, N. F. (1998). Marketing implementation: the implications of marketing paradigm weakness for the strategy execution process. Journal of the Academy of Marketing Science, 26(3), 222-236. doi: 10.1177/0092070398263004

Piercy, N. F. (2005). Implementação de marketing, mudança organizacional e estratégia de marketing interno. In M. J. Baker (Org.), Administração de marketing (5 ed. pp. 378-399). Rio de Janeiro: Elsevier/Campus.

Porter, M. E. (1986). Estratégia competitiva: técnicas para análise de indústrias e da concorrência (7a ed.). Rio de Janeiro: Campus.

Porter, M. E. (1999). On competition: estratégias competitivas essenciais (7a ed.). Rio de Janeiro: Editora Campus. 
Processos de Implementação de Estratégias de Marketing na Indústria Criativa de Jogos Eletrônicos

Reis, A. C. F. (2007). Economia da cultura e desenvolvimento sustentável: o caleidoscópio da Cultura. Barueri: Manole.

Reis, A. C. F. (2008). (Org.). Economia criativa como estratégia de desenvolvimento. Uma visão dos países em desenvolvimento. São Paulo: Itaú Cultural.

Sashittal, H. C., \& Jassawalla, A. R. (2001). Marketing implementation in smaller organizations: definition, framework, and propositional inventory. Journal of the Academy of Marketing Science, 29(1), 50-69. doi: 10.1177/0092070301291004

Slater, S. F., Hult, T. M., \& Olson, E. M. (2010). Factors influencing the relative importance of marketing strategy creativity and marketing strategy implementation effectiveness. Industrial Marketing Management, (39), 551-559. doi:10.1016/j.indmarman.2008.03.007

Slater, S. F., \& Olson, E. M. (2001). Marketing's contribution to the implementation of business strategy: an empirical analysis. Strategic Mangement Journal, 22(11),1055-1067.

Toaldo, A. M. M. (2004). Formação da estratégia de Marketing: a construção de um modelo teórico. (Tese de doutorado), Escola de Administração, Universidade Federal do Rio Grande do Sul, Porto Alegre, RS, Brasil.

Toaldo, A. M. M., Jotz, C. B., \& Luce, F. B. (2008). O papel do grupo de trabalho na formulação e implementação de estratégias. Revista de Gestão USP, 15(4), 101-115.

Tschang, F. T., \& Vang, J. (2008). Explaning the spatial organization of creative industries: the case of the U.S Videogames Industry. Proceedings of the Celebration Conference 2008 on Entrepreneurship and Innovation, Copenhagen, Denmark, 25.

United Nations Educational, Scientific and Cultural Organization; Global Alliance for Cultural Divercity. (2006). Understanding creative industries: cultural statistics for public policy-making. $\begin{array}{lllll}\text { Recuperado em } & 15 & \text { outubro, } & 2008, & \text { de }\end{array}$ http://portal.unesco.org/culture/en/files/30297/11942616973cultural_stat_EN.pdf/ cultural_stat_EN.pdf

Varadarajan, R. (2010). Strategic marketing and marketing strategy: domain, definition, fundamental issues and foundational premises. Journal of the Academy of Marketing Science, 38(2), 119-140. doi: 10.1007/s11747-009-0176-7

Varadarajan, P. R., \& Yadav, M. (2002). Marketing strategy and the internet: an organizing framework. Journal of the Academy Marketing Science, 30(4), 296-312. doi: $10.1177 / 009207002236907$

Voss, G. B., \& Voss, G. Z. (2000). Strategic orientation and firm performance in a artistic environment. Journal of Marketing, 64(1), 67-83. doi: 10.1509/jmkg.64.1.67.17993 
Wensley, R. (2005). Os conceitos básicos da estratégia de marketing. In M. J. Baker (Org.), Administração de marketing (5a ed. pp. 378-399). Rio de Janeiro: Elsevier, Campus.

Whittington, R. (1996). Strategy as pratice. Long Range Planning, 29(5), 731-735.

Yin, R. K. (2005). Estudo de caso: planejamento e métodos (3a ed.). São Paulo: Editora Bookman.

Recebido: 10/03/2013

Aprovado: 26/04/2013 